\title{
International Negotiation Simulations: An Examination Of Learning Processes And Outcomes
}

\author{
Ron Lennon, (Email : rlennon@mail.barry.edu), Barry University \\ Alex Sharland, Barry University \\ Mauricio Gonzalez, Tecnologico de Monterrey University System, Mexico
}

\begin{abstract}
Negotiation skills are valuable tools especially in the international business context. However, the extent to which negotiation simulations build new skills rather than augment existing skills is unclear. This empirical study focuses on the extent to which Mexican students and U.S. students learned from a negotiation simulation. The results indicate that all students learned something but that the Mexican students learned more.
\end{abstract}

\section{INTRODUCTION}

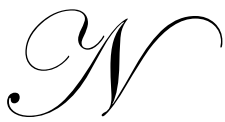

egotiating is a "universal" business skill used in virtually all business cultures [Kennedy 1994]. A simulation helps prepare college students better for the working world by giving them an environment in which they can learn to make good quality decisions. Having college students negotiate within a simulated business context is a combination that is excellent preparation for future business careers. Upon graduation, many students find that their ability to make good quality decisions is critical to their future business success. Given the nature of today's business environment, where international business is often the norm rather than the exception, developing negotiating skills for cross-border business is more important than ever.

The research available in negotiation simulations (especially the case for international negotiations), rarely examines what and how much is learned during the simulation. For instance, how much is learned when developing these business skills, and how does it impact making better decisions? After all, many college students bring some prior level of negotiation skill by virtue of their background or employment experience. College educators cannot be sure whether the process reinforces existing traits or develops new ones. We need to know more about how the learning process works in negotiation simulations, and build upon that base to make the experience more effective. Before we can improve learning through the use of simulations we must first establish that college students actually learn using simulations.

The following paper addresses this particular issue. That is, to what extent do college students improve their decision making skills through participation in an international negotiation simulation exercise? The paper is presented in four sections. The first discusses the literature on the value of simulations. The second identifies the methodology used in the current empirical study. The third presents the results of the study. The fourth discusses the conclusions and makes specific recommendations.

\section{LITERATURE REVIEW}

Simulations can be a useful instructional tool in many classrooms. McKeachie [1994] argues that the "chief advantage of games and simulations is that students are active participants rather than passive observers. Students must make decisions, solve problems, and react to the results of their decisions.” Active learning requires students to be involved and participate, in contrast to "chalk and talk" lecturing in which students need not do anything and may disengage from class [Becker and Watts, 1996]. 
Dekkers and Donatti [1981] suggest that simulations have a positive effect on student motivation. Because they are actively involved, college students are engaged in the learning process rather than observers. Parente [1995] argues that simulations can "build an environment from which students can learn experientially". Therefore, college students analyze situations from the inside, or the position of a participant. By making students active learners, we motivate them to learn the material and succeed in the class. They also learn to view the material with a more critical eye as they make decisions themselves rather than passively accepting those made by others.

Classroom simulations have been found to facilitate a deeper understanding of complex concepts [Dorn 1989; Dukes 2001; Jenkins 1992]. Through reflection on direct experience, these exercises provide students with insights difficult to achieve through conventional pedagogical techniques.

In the case of simulations as an instructional tool for teaching negotiations, in college situations the authors found no specific literature directly related to this field. However, based on literature related to training in organizations, we expect that simulations will have a positive effect when teaching college students how to negotiate. Simulations based on role playing are a common method for training in organizations when developing human relation skills is required (Bass \& Vaughan, 1966, Goldstein, 1992). In a negotiation, the use of effective interpersonal skills is crucial. However, these skills are difficult to acquire by cognitive methods alone (e.g. attending lectures or reading). In other words, college students have a more complete learning experience in a role-playing negotiation (King, 1966, Goldstein, 1992).

Despite the explosion of global business in the last 20 years, the researchers found almost no literature on the subject of international negotiation simulations. There is much work on the relative importance of cross-border negotiation (cites). However, almost nothing was found related to simulations, and especially simulations in the college environment. Given the likelihood of graduates working in an international/global world, the dearth of literature was surprising.

In summary, negotiation simulations seem to be a positive learning experience for college students. These exercises actively engage students' attention, make them more involved, and enhance/augment the communication skill base. Little, if any, of the extant literature addresses the extent to which students learn something (technical or communication skills) during the simulation. Further, the researchers determined that analyzing the above research question in the international/cross border context would be a (hopefully) significant contribution to the current body of knowledge. The following describes an empirical study directed at this void.

\section{SIMULATION METHODOLOGY}

The purpose of the current research is to demonstrate a methodology by which students become better decision makers, and quantify their learning outcomes. This section examines four components of the simulation methodology; a) simulation format, b) student selection, c) simulation administration, and d) quantification.

\section{Simulation Format}

The simulation was custom-developed for a Channels of Distribution course in the Marketing curriculum. It is an individual exercise that gives one college student the opportunity to negotiate against another. The simulation establishes an initial buyer and seller position with a fictitious scenario, a reporting structure, and financial incentives to succeed (both personal and organizational). Perhaps most importantly, it provides a win-win solution for each party. That is, the scenario allows both parties to negotiate to a position where both the buyer and seller can achieve all their goals (as set within the scenario) provided they engage in a quid pro quo. The final result requires the negotiation of a specific contract price, payment dates, delivery dates, and after-sales service contracts. Each of these elements has a cost and has to be factored into the final calculations. The simulation takes place over a number of weeks, and students are not allowed to discuss the scenario with other students except in the classroom with the instructor present. When the simulation is conducted on a single campus, this discipline is imposed by virtue of the fact that neither party knows who their negotiating counterpart is. That is, students write anonymously to each other and hand in their bids and positions to the instructor who acts as an agent/intermediary. There are three rounds of 
letters prepared by the students as a formal response to their counterparty. The idea for this is to improve students' ability to communicate formally in the letter format.

\section{Student Selection}

In past administrations, the simulation was conducted on one campus (a small university in the Southeastern United States) as part of the Channels of Distribution course. For the current study, another university in Northern Mexico was included. As noted above, there is a dearth of studies analyzing cross-border negotiation simulations. Marketing students from each university were participants in the simulation. The students at the US College were enrolled in a Channels of Distribution course. The students in Mexico were enrolled in a negotiation course. The simulation was started early in the semester to provide all students the opportunity to become equally familiar with the scenario. There were 18 students in each location. All participants in the study were well versed in both the written and verbal forms of English.

\section{Simulation Administration}

At the outset, it was determined that all US students should be sellers and all Mexican students' buyers. Ideally, there would have been a mix of buyers and sellers at each location. However, there were two reasons why the "specialization" route was chosen. First, from a research perspective, an empirical study with nine in each cell is not enough to run a statistical analysis of any power. By forcing all US students to be sellers, and all Mexican students to be buyers, the cell sizes rose to eighteen. Second, specialization alleviated the incentive to cheat by removing the opportunity for students to "see the other side" of the equation. In a "one location" run, the instructor can monitor (to a certain extent) the 'leakage' of information across the buyer/seller dyad. This is much more difficult when multiple instructors and locations are involved. The participants were given contact information for their designated counterpart. Most of the negotiations proceeded using email. One buyer-seller dyad used the telephone. The simulation took place over a period of 6 weeks. The three rounds of the negotiation were recorded via letters from buyer to seller and vice-versa to improve student communication skills. Following the final round, all conditions of the negotiation scenario were agreed. That is, the contract price, payment dates, delivery dates and after sales service arrangements.

\section{Quantification}

As noted in the literature review, there is almost no empirical evidence focusing on the learning process or outcomes for negotiation simulations; especially so for cross-border scenarios. The researchers decided that a pretest/post-test methodology would be necessary to identify the difference "caused" by the simulation.

Students were given a pre-simulation instrument addressing their prior experience of computer technology, work experience, negotiating, international business and travel experience, age, gender, and other demographic information. As part of the pre-test instrument, all buyers and sellers were provided with two scenarios (see Appendix A), requiring them to make decisions about bidding in negotiation situations. Once the final decisions were made in the negotiation simulation, all students were given a post-simulation instrument. This assessed student perceptions of the simulation, and re-presented the two prior scenarios. The expectation was that if students learned from the simulation then their responses to the two prior scenarios would be different. 


\section{EMPIRICAL STUDY}

The central research question at the heart of the study is "to what extent do college students improve their decision making skills through participation in an international negotiation simulation exercise?” The researchers used students from two different universities in two countries to assess the learning effect of a simulation on different student groups. The central aim was to enhance the value of the study by establishing that students from multiple learning systems and environments confirm the value of a negotiation simulation. Based on the research question developed above, the following hypotheses are the basis of the empirical study.

H1: Participation in the negotiation exercise improves a student's negotiation skills?

This seems an obvious statement, but if the simulation does not result in a better skill base than any other conclusions are likely to be faulty. The researchers anticipate (a priori) that all students will demonstrate better negotiation skills after participating in the simulation.

H2: Mexico-based students respond differently to the negotiation exercise than US-based students?

Given that negotiation is a "universal" business skill, there is the possibility that 'culture' may explain different learning rates and results. Moreover, with students drawn from different educational and cultural backgrounds, examining this aspect of the study is not just necessary but vital.

H3: The negotiation exercise has a bigger effect for students with more work experience?

The issue here is that because negotiating is a "universal" business skill, if a student has already learned to negotiate 'on-the-job', s/he will perform better than a student without such prior learning opportunities. This hypothesis also presupposes that some knowledge of business negotiation provides a base for better performance on the simulation.

\section{RESULTS}

The premise of the research, as set out above, is that,

- $\quad$ students learn to improve their negotiation technique as a result of participating in the negotiation simulation, - $\quad$ there is likely to be a difference in the learning effect between the Mexican and US students, and - $\quad$ there is likely to be a 'work experience' effect, where people with more work experience are better negotiators during the simulation.

The premises are tested using the three hypotheses developed in the earlier section. The descriptive statistics for each group are set out in Table 1. There appears to be little difference between the two groups. The sample size is small, but there is only one statistical difference between the groups on the categories below. The age distribution of the US students included more "older" students with only a few being 21. Most of the Mexican students were 21, with a couple of much older (age 29) students shifting the mean. The only major difference between the groups is in the area of part-time work experience $(\mathrm{F}=7.273 ; \mathrm{p}=.011)$. US students have significantly more part-time work experience. None of the students had direct experience with business negotiation. The number of students with significant full-time work experience was small and the cell sizes were inadequate for the empirical tests. Therefore, Hypothesis 3 was not examined in further detail. 
Table 1: Descriptive Statistics for Student Groups

\begin{tabular}{|l|c|c|c|c|}
\hline & \multicolumn{2}{|c|}{ US Students } & \multicolumn{2}{c|}{ Mexican Students } \\
\hline Gender & \multicolumn{2}{|c|}{ Male (7) Female (11) } & \multicolumn{2}{c|}{ Male (8) Female (10) } \\
\hline & Mean & S.D & Mean & 7.12 \\
\hline Age & 22.28 & 4.735 & 21.72 & 1.383 \\
\hline Years PT Experience* & 2.72 & 2.63 & 0.83 & 1.674 \\
\hline Years Internship** & 2.94 & 6.073 & 0.73 & \\
\hline
\end{tabular}

* Significantly different at the.05 level

** Too few Mexican students

The pre- and post-simulation scenario results provide some interesting information. These results are shown in Table 2. Scenario A was constructed in such a way that the researchers anticipated those with better negotiation skills would offer a lower bid at first and then expect to pay close to $\$ 4,200$. In Scenario B, the "baseline" (the highest amount offered) was expected to be $\$ 64$.

Scenario A: all students became more "aggressive" with their second bids. They offered a lower first bid post-test than they did pre-test. The US students (as a group) expected to pay almost exactly $\$ 4,200$. The Mexican students believed they could acquire the car for less than $\$ 4,200$, post-test.

Scenario B: students were expected to cluster their bids around \$64, given that that was (approximately) the 'substitution' price. There were some differences here resulting in a statistically significant ANOVA for the pre-test result (see below). US students were much more aggressive in their bids pre-test, and still did not approach the expected price in their post-test offer. Mexican students appeared to be more timid in the pre-test offer and became much more aggressive post-test. The implications of these scenarios are discussed below.

Table 2: Pre- and Post-Test Scenario Results

\begin{tabular}{|l|c|c|c|c|}
\hline & \multicolumn{2}{|c|}{ US Students } & \multicolumn{2}{c|}{ Mexican Students } \\
\hline Scenario & Pre-Test & Post-Test & Pre-Test & Post-Test \\
\hline A First Offer (\$) & $3894(435.86)$ & $3778(371.89)$ & $3902(327.41)$ & $3612(418.52)$ \\
\hline A Expect To Pay (\$) & $4269(345.19)$ & $4205(331.17)$ & $4173(295.34)$ & $4034(354.9)$ \\
\hline B Bid(\$) * & $57.50(10.44)$ & $62.14(6.54)$ & $64.24(5.78)$ & $60.38(8.56)$ \\
\hline
\end{tabular}

* Pre-Test Difference (F=5.730; $\mathrm{p}=.022$ ) No Post-Test Difference

\section{Simulation Results}

The group results of the simulation itself are depicted in Table 3. The simulation is structured so that a winwin solution exists. The individuals have personal as well as group/company goals, and these are achieved by seeking not only a specific price, but also negotiating the timing of payments and delivery dates. The win-win solution in terms of final price is $\$ 1,250,000$. Buyers are trying to achieve a price less than this; sellers more than this.

In general, the Mexican students demonstrated better skills in the simulation. Only one dyad achieved the overall win-win solution, all others agreed to a final price of less than $\$ 1,250,000$. However, the conclusion that the buyers out-negotiated the sellers only holds if all participants were fully committed to the goals of the simulation, and had an equivalent level of understanding. The instructors in both locations made sure that students understood that full participation was essential, and that a significant part of the grade was dependent on complete commitment to the exercise. There was no evidence that the buyers understood the simulation better. Therefore, the researchers conclude that in this instance the Mexican students were better negotiators. 
Table 3: Simulation Bids

\begin{tabular}{|l|c|c|c|c|}
\hline & Bid 1 & Bid 2 & Bid 3 & Final Price \\
\hline Buyer (Mexico) & $\$ 1,007,222$ & $\$ 1,143,681$ & $\$ 1,186,833$ & \\
\hline Seller (US) & $\$ 1,221,139$ & $1,201,694$ & $\$ 1,365,764$ & \\
\hline Final Contract & & & & $\mathbf{\$ 1 , 1 9 6 , 5 0 0}$ \\
\hline
\end{tabular}

Using self-reported data in the post-test data collection, the vast majority of students agree that their negotiation skills were improved (94\%), they found this exercise useful (94\%), and that they would take another course using such an exercise (97\%). The extent to which their skills were truly improved is shown in Table 2. In both groups, there was a difference in the bids for both scenarios indicating that although no new information was available to the students, they processed the information differently; that is, they "learned" from the simulation.

Figures 1, 2, and 3 show the "learning effects" resulting from the simulation. In both Figures 1 and 2, both groups achieve a downward slope indicating that they bid lower on the post-test than they did on the pre-test. However, the slope for the Mexican students is steeper. One conclusion that can be drawn is that the Mexican students experienced a stronger "learning effect" than the US students, as evidenced by the results shown in Table 3.

Figure 1: Scenario 1 First Bid

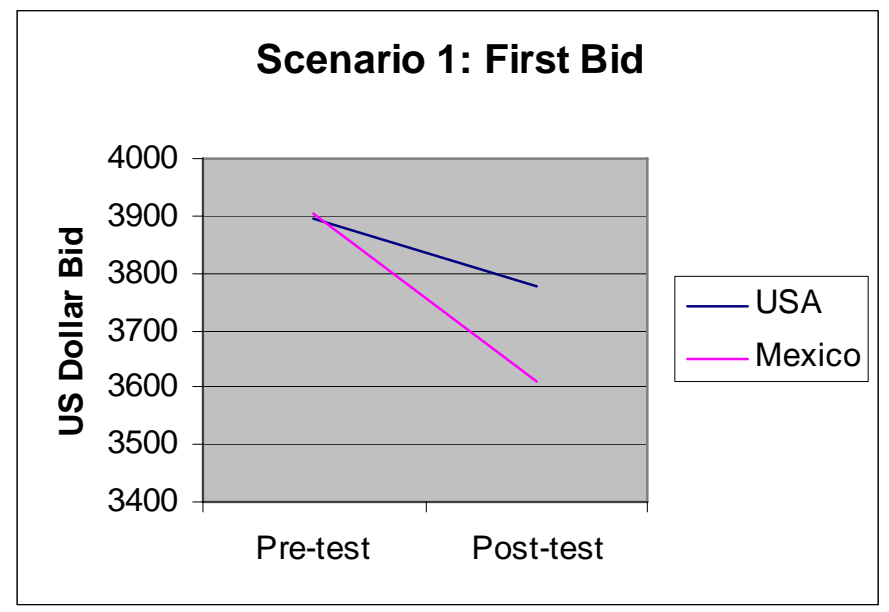


Figure 2: Scenario 1 Expect to Pay

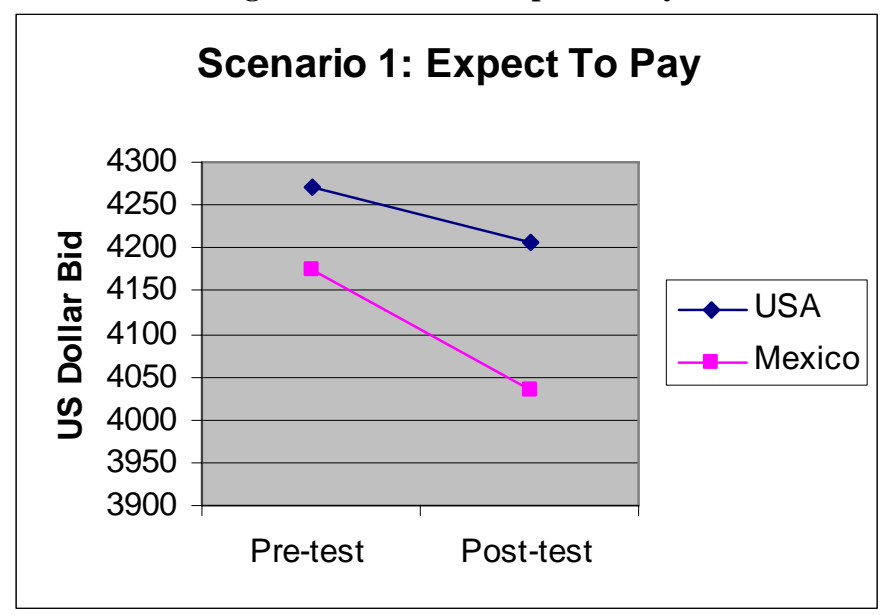

Figure 3: Scenario 2 What do you bid?

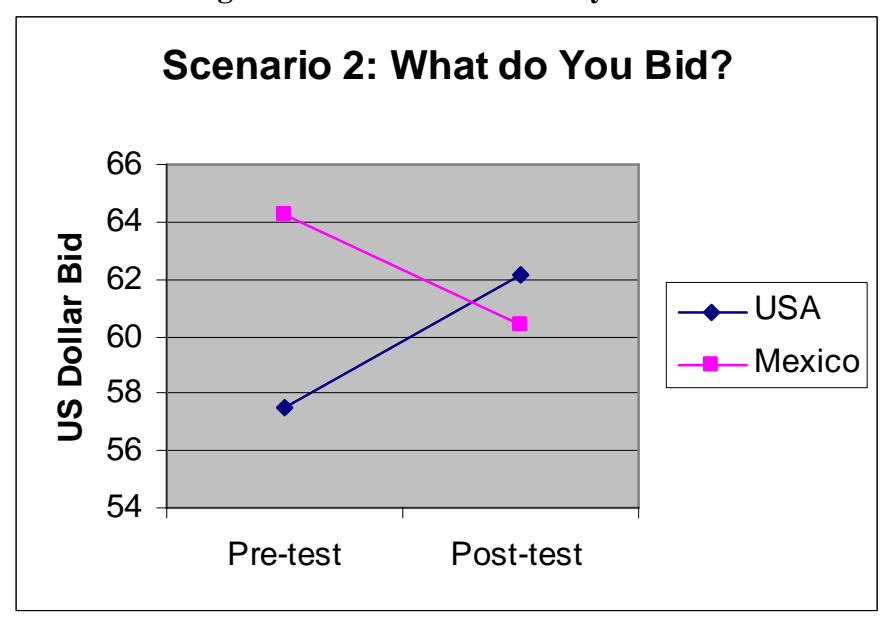

In the second scenario (shown in Figure 3), we find an unusual result. That is, the slopes of the student groups are opposite. The US students changed their bid to a higher level. They learned that they could not be so aggressive and achieve their goal. The Mexican students learned that they could be more aggressive and still achieve their goal.

\section{CONCLUSIONS}

Students appeared to learn from the negotiation simulation exercise, and should be able to apply what they have learned to the "real" world of work. Employers ask for these types of skills and students having completed this exercise should have a "leg up" on the competition. Furthermore, an international negotiation exercise appears to be better than a domestic negotiation exercise because of the additional complexity of dealing with international business elements. The 'complexity' appeared to be within the grasp of most students given an appropriate structure within which to operate. 
In terms of the hypotheses, Hypothesis 1 was supported by the data. That is, the students experienced an improvement in negotiation skills. Hypothesis 3 was not supported. The cell sizes for those with work experience were too small and the tests were inconclusive.

Hypothesis 2 was supported in that there was a difference between the experience of the Mexican students and the US students. A plausible explanation for this difference resides in the cultural differences between Mexican and US negotiation styles. We were unable to find any direct evidence on the effectiveness of Mexican and US crosscultural negotiations. We found evidence on the effectiveness of other cultures negotiating with Mexicans. For example, Natlandgmyr and Rognes [1995] found that Norwegian negotiators reached lower outcomes negotiating with Mexicans than negotiating with their Norwegian counterparts. As for the comparison between Mexican and US negotiators, most of the literature reports differences in the negotiation outcomes and processes comparing Mexican dyads with American Dyads [Adler Graham and Schwarz 1987]. That is, comparisons of country intra-cultural negotiations. In this sense, Lewicki, Saunders, and Minton [2001] conclude that, for the most part, the differences in cross-cultural negotiations reside in the process and not necessarily in the outcome. In the particular case of the US and Mexican negotiation reported in our study, we believe that risk propensity and orientation to time may have played a major role in the outcome. Lewicki, Sounders and Minton [2001] argue that in cultures where time per se is not important, like Latin American cultures, the focus is on the task regardless of the time it takes to complete it. Additionally, they believe that in risk avoiding cultures (like Mexico) negotiators seek more information before making a decision and tend to take a "wait-and-see" stance whereas risk oriented cultures (like the U.S.) are willing to commit earlier in the negotiation. In this sense, we found that some Mexican students complained to the Mexican professor that their US counterparts were forcing an early solution, well before the date line established in the simulation. They argued that they needed more time to do the negotiation. This difference in approach may have caused the difference in outcomes.

\section{LIMITATIONS AND RECOMMENDATIONS}

Since this was only a very limited sample of marketing students, additional research needs to be completed on both domestic and international aspects of this topic.

The students came from private universities, and there is the possibility that a similar study at a public institution would develop different results. Similarly, students in other business discipline areas may perform differently. Further, the elements of culture were not measured and tested in the current work. It is possible that any learning differences between the Mexican and US students are correlated with one or two 'cultural variables'. Identifying these variables will help students perform better in negotiation scenarios both inside and outside the classroom.

The net effect for all participants in this exercise was positive. In terms of developing 'real world' business skills, a negotiation simulation appears to perform very well. Colleges and Universities without such elements in their curriculum should consider changes to their Business school requirements. Including one International negotiation exercise, especially for Marketing students, would appear to be invaluable.

\section{REFERENCES}

1. Adler, N.J., Graham, J.L., and Schwarz, T. Business negotiations in Canada, Mexico and the United States. Journal of Business Research, (1987) 15, 411-429.

2. $\quad$ Bass, B. M., \& Vaughan, J. A., Training industry: The management of learning, (1966) Belmont, C.A. Wadsworth

3. Becker, W.E. and Watts, M. Chalk and talk: A national survey on teaching undergraduate economics. American Economic Review 86 (May 1996) pp.448-53.

4. Dekkers, J. and S. Donati The integration of research studies on the use of simulation as an instructional strategy. Journal of Educational Research (1981) 74: 424-7.

5. Dorn, D. Simulation Games: One more tool on the pedagogical shelf. Teaching Sociology_(1989) 17: 1-18. 
6. Dukes, R. ed. Simulation and Gaming and the Teaching of Sociology $8^{\text {th }}$ ed. Washington, DC: American Sociological Association. (2001).

7. Goldstein, I. L. Training in Organizations, (1992) Pacific Grove, California. Brooks / Cole Publishers

8. Jenkins, A. Active Learning in Structured Lectures. in: Teaching large classes in higher education. Edited by Graham Gibbs and Alan Jenkins. (1992), pp. 63-77 London, England: Kogan Page.

9. $\quad$ King, P.H. A summary of research in training for advisory roles in other cultures by the behavioral sciences laboratory. (AMRL - TR - 66 - 131) (1966) Wright-Patterson Air Force Base, OH: Aerospace Medical Research Laboratories.

10. Lewicki, R.J., Sounders, D.M., and Minton, J.W. Essentials of Negotiation_2 $2^{\text {nd }}$ edition. (2001) McGraw Hill.

11. McKeachie, W. J. Teaching Tips: Strategies, research and theory for college and university teachers, $9^{\text {th }}$ ed. (1994) Lexington, MA: D.C. Heath.

12. Natlandmyr, J.H., and Rognes, J. Culture, behavior, and negotiation outcomes: A comparative and crosscultural study of Mexican and Norwegian negotiators. The International Journal of Conflict Management, (1995) 6, 5-29.

13. Parente, D. H. A large-scale simulation for teaching business strategy. In: Simulation and gaming across disciplines and cultures, ed. D. Crookall and K. Arai, (1995) pp.75-82. Thousand Oaks, CA: Sage publishers.

\section{Appendix A}

\section{Scenarios A \& B}

Now we have two scenarios we would like you to respond to. Please read the scenario then answer the questions below each scenario.

\section{SCENARIO A}

You are buying a used car from a private individual. The condition of the car is good, the color and model are what you want. You are very interested in purchasing this car. The advertised price is US\$5,000. The trade-in /book price* for private sales is US\$4,200.

a) What is your first offer?

b) What do you expect to end up paying for the car?

*Various online sources are available that estimate what a car is worth in a sale to a dealer or via private sale. The price above is what the web sites believe is the appropriate price for this car.

\section{SCENARIO B}

It is the beginning of a new semester and you want to buy the books for a particular course. There are two books required.

The new price for the books in the University bookstore is US\$100 and US\$35.

The used price for the books in the University bookstore is US\$50 and US\$20.

The online used book price is US\$47 and US\$17.

A fellow student has posted a "for sale" notice on the bulletin board offering these books for the best price. You know there are 3 other parties interested in these books. You can only place one offer.

What do you bid? 
NOTES 